\title{
ROLE OF INTEGRATED VIRTUAL E- LEARNING SYSTEM FOR DISTANCE LEARNING STUDENTS
}

\author{
Ms.Shweta Soni ${ }^{1}$, Prof.M.D.Katkar ${ }^{2}$ \\ ${ }^{1}$ (M.tech. $4^{\text {th }}$ sem, Department of Computer Science and Engineering, G.H.Raisoni \\ Institute of Engineering and Technology for Women, Nagpur, India) \\ ${ }^{2}$ (Prof. Department of Computer Science and Engineering, G.H. Raisoni Institute of \\ Engineering and Technology for Women, Nagpur, India)
}

\begin{abstract}
This paper entitled Role of Integrated Virtual E-Learning System for Distance Learning Students is mainly for all educational colleges such as engineering colleges and others where there is connection between faculty and student. In colleges, sometimes there may be loose connection between faculty and students. Some students cannot attend the class due to some reason such as missing lectures due to illness or some personal reason, doing part time job along with study, disable person. Those student who cannot attend the class or miss some lecture or any lab activity they can download the lecture file or they can download the video so that they can better understand the concept. If any important notice teacher want to give to the student teacher can upload it on notice board so that student can get the alerts immediately on her notice board. Admin maintain and update the system database like all student information, all Lecture information, all assignment information like view previous assignment, all lab manuals and maintain the database of each student with his attendance and which class he belong with his personal information and admin also maintain the user login details also to calculate the student attendance. We are attempting to improve our existing system that runs generally by pen and paper now a day. We design a virtual system which is run without pen and pencil. It is basically designed for student who are unable to attend the class due to some reason like disable person. For that, it will help them to view lecture, view assignment at any time and getting important notice and alerts for students. we try to offer a range of facilities in this system that will maintain all student, and lecture records in a much more efficient way with less work.
\end{abstract}

\section{KEYWORDS}

Virtual System, Study Material, File Upload, Video Upload, Interactive Education.

\section{INTRODUCTION}

Today a number of website exist in world wide web online database which having very excellent study materials and information and they are very useful for any student related to study, for example those student who want to do MS from USA, www.usnews.com is a very good website for them. These website provide college information and related thing upon subscription taken. Now suppose I have some question which is very confusing in selecting colleges then what will I do.? I will go to other website to get information. In that time this subscription doesn't work. This type of problem is due to lack of interactive response and face to face communication.

In this project, we have designed virtual class system software which will provide all information about students and lecture files and video lecture. Some of students which are unable to attend the

DOI : $10.5121 /$ ijnsa.2014.6306 
International Journal of Network Security \& Its Applications (IJNSA), Vol.6, No.3, May 2014

class due to some reason such as doing job, attending conference somewhere, or due to his disability. Some of students are unable to study due to financial problem. So this system is very useful for them and they choose distance learning education and which is available $24 * 7$. If student miss the lecture than they can regularly view lectures, view video lecture, view lab manual, get important notice on notice board, assignment. When we talk about regular students than this system is also useful for those if they can miss the lecture than they can download the lecture. we have provide the facility to student if student have doubt then there is green and red symbol on user screen after login and if admin online then they can send her query from feedback option. So that admin can get her query immediately and solve it as early as possible. This virtual system is available anytime without any restriction that means we can access 24 hours a day. We can share files, videos and many more.

\section{Difficulty In Existing System}

1. Less User Friendly: The existing system is less user friendly because the retrieval and storing of data is not fast efficient. And data is not maintained efficiently.

2. Not Useful for E Learning and disable Student: Those students who want to continue their study while doing job or having some disability, so they can't get benefit because they have to attend the class regularly.

3. Difficulty in report generating: We require more calculations to generate the student report so it is generated at the end of the session.

4. Manual control: All calculations to generate student report are done manually so there is greater chance of errors.

5. More time require: Every work is done manually so time required more.

\section{Proposed system}

1. More User Friendly: - The Virtual system is user friendly because the retrieval and storing of data is fast efficient. And data is maintained efficiently.

2. Very useful for E-learning and disable student: This system useful for those students those who cannot attend the class due to some reason like doing job or due to his disability and if these students wants to continue their education then this system is very useful for them because this system provide the opportunity to such type of students those who wants to continue their education along with their job. There is no need to present physically for that purpose we call this system Virtual E-Learning System and there is no restriction. We can access this system 24*7.

3. Reports are easily generated: Student Reports can be easily generated in the proposed system like when was student login and on which date he is login which is used for student attendance calculation by weekly, monthly. So student can generate the report as per the requirement (monthly) or in the middle of the session. Admin can update the notice time to time for the students regarding their attendance, exam, important notice.

4. Computer operator control: There is no chance of errors. And storing and retrieving of information in virtual system is easy. And interactive for students. 
International Journal of Network Security \& Its Applications (IJNSA), Vol.6, No.3, May 2014

\section{System Architecture of Virtual E-Learning System}

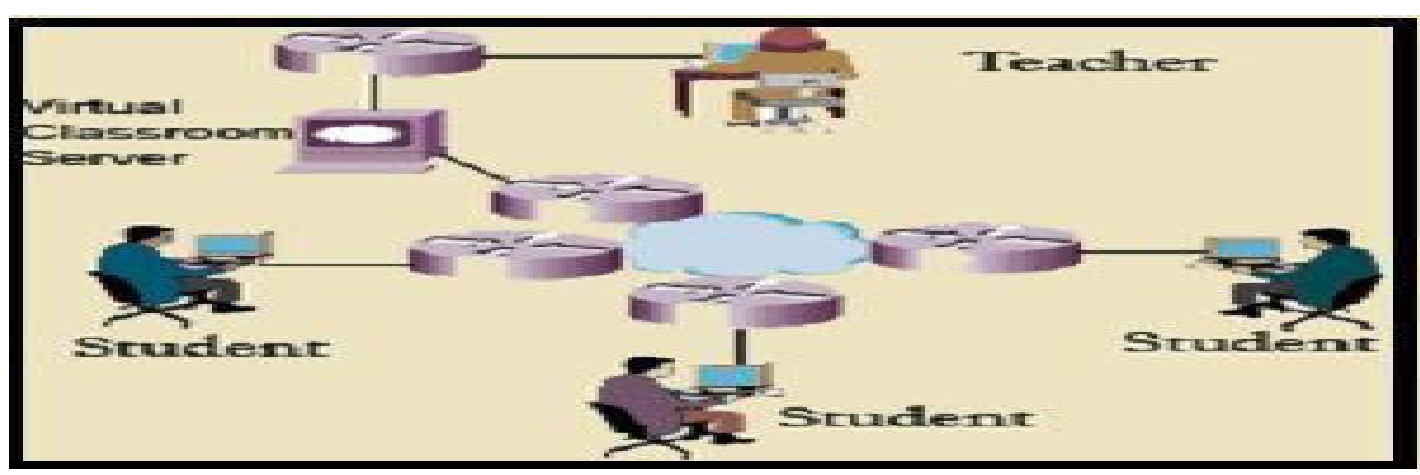

Fig 1: System Architecture of Virtual E-Learning System

The system architecture of Virtual E-Learning System shows that the admin act as a teacher who can update the whole information in virtual system. And student who can access those data for knowledge and education purpose. No of student get different user name and password so that they can access this virtual lab at a time at different places. And admin can observe the each activity of student.

\section{Implementation of the Project with Some GUI's.}

Administrator Page:

Firefox $-M$ Gmail - Scan copies of receipt $\quad x \mid O$ Admin
+6 www.ppt.net.in/admin/

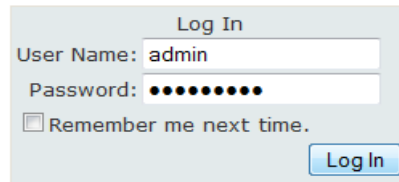

Fig 2: Admin Login

Admin enter user name and password to change the database of virtual system. We provide the security to the admin also. So that our database is more secure.

Student registration by Administrator: 
International Journal of Network Security \& Its Applications (IJNSA), Vol.6, No.3, May 2014

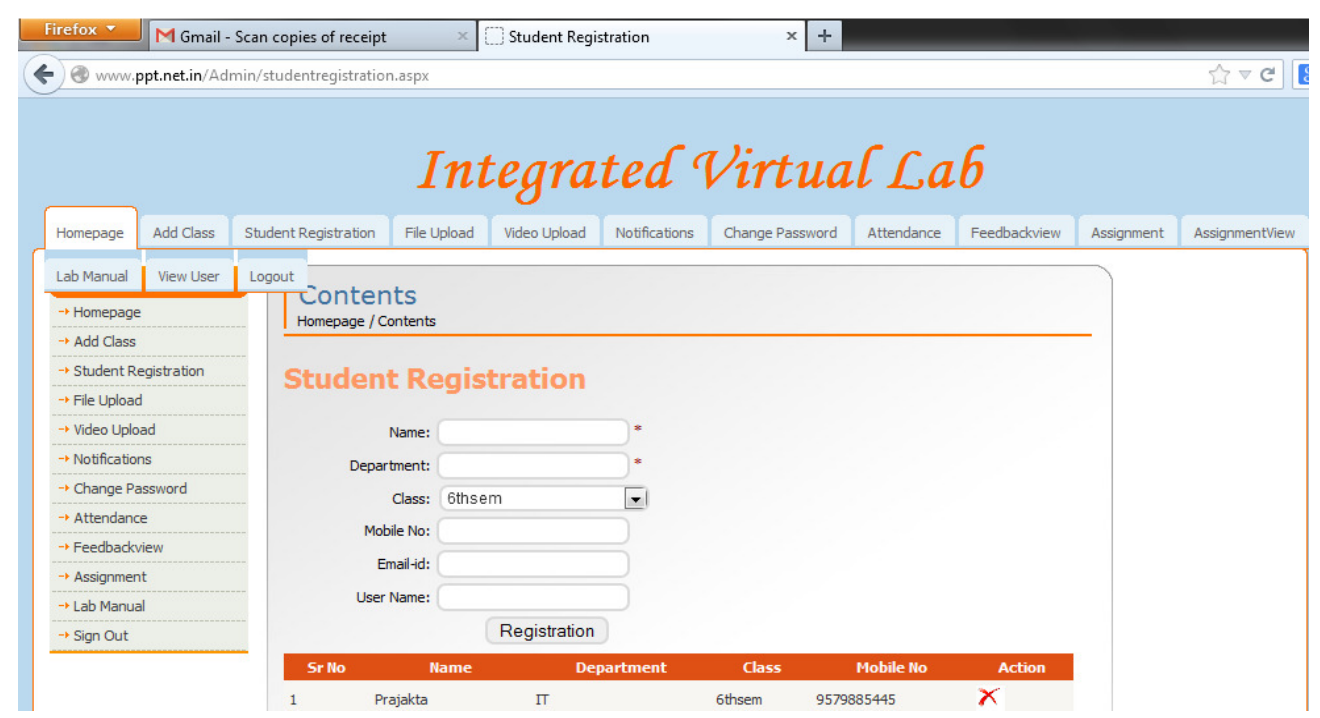

Fig 3: User Registration Form

\section{Upload File by Administrator:}

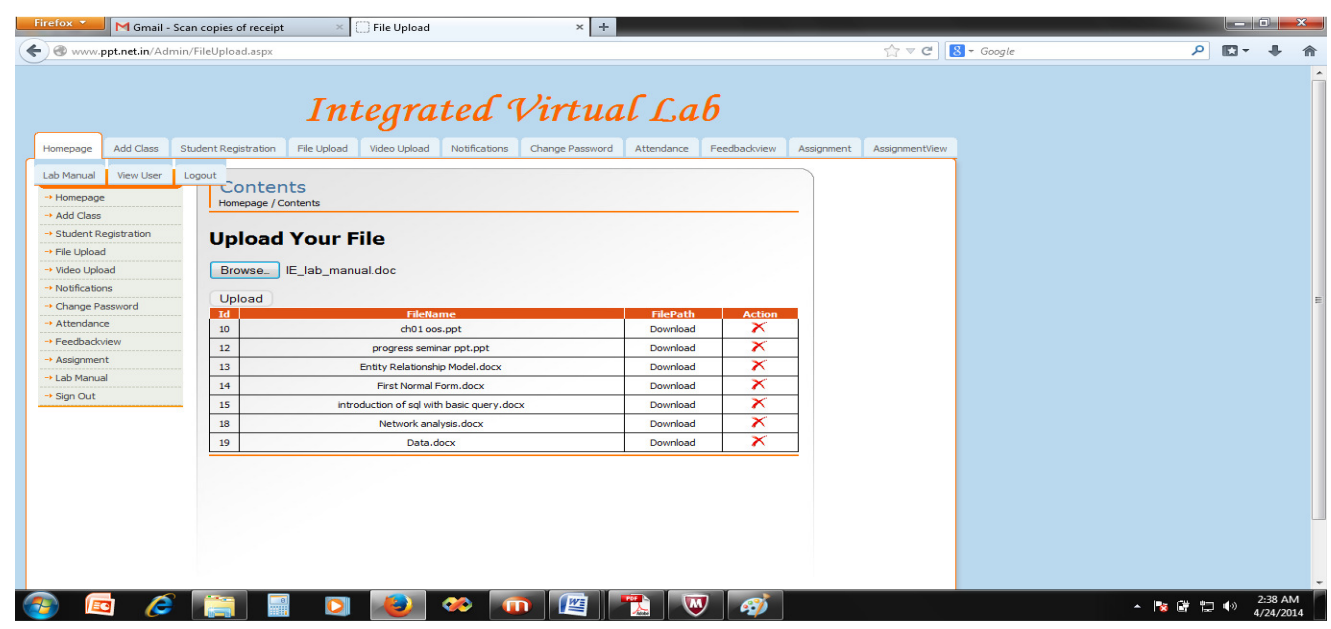

Fig 4: Select file to upload and delete file if admin want. 
International Journal of Network Security \& Its Applications (IJNSA), Vol.6, No.3, May 2014

\section{Video Uploaded Successfully:}

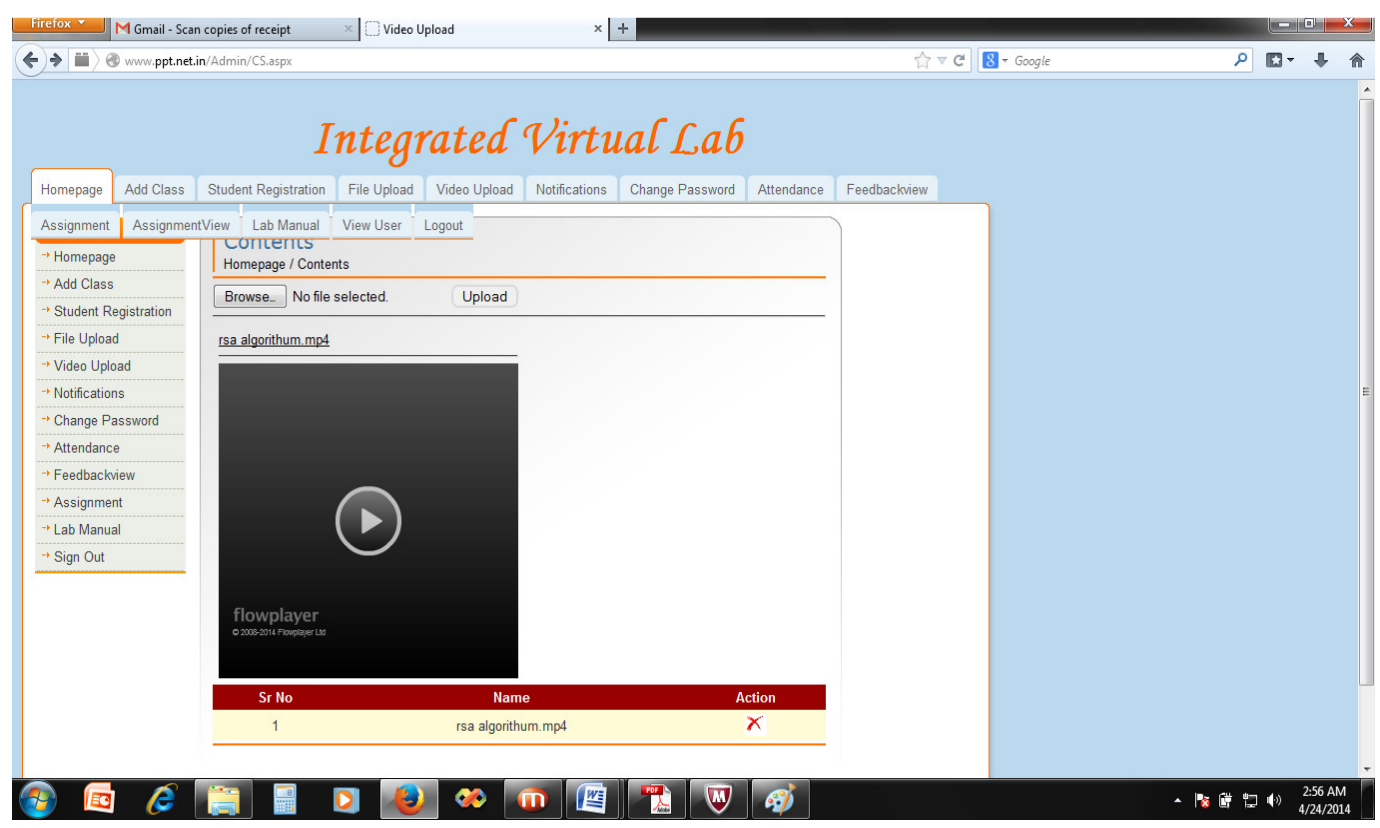

Fig 5: Upload Video and video uploaded successfully.

\section{Enter Notification by Administrator:}

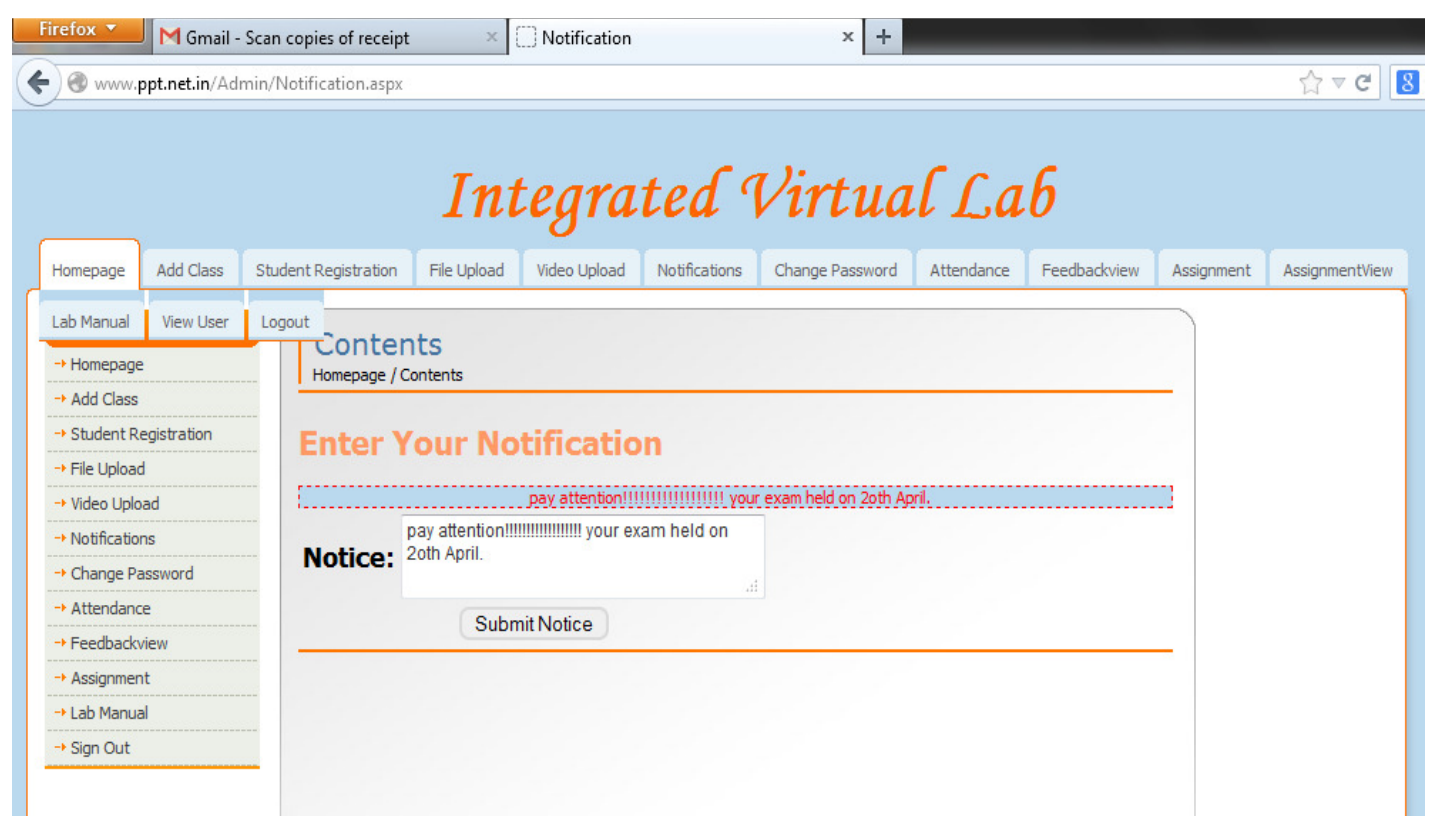

Fig 6: Enter Notice for student by admin. 
International Journal of Network Security \& Its Applications (IJNSA), Vol.6, No.3, May 2014

\section{View user login details with date and time:}

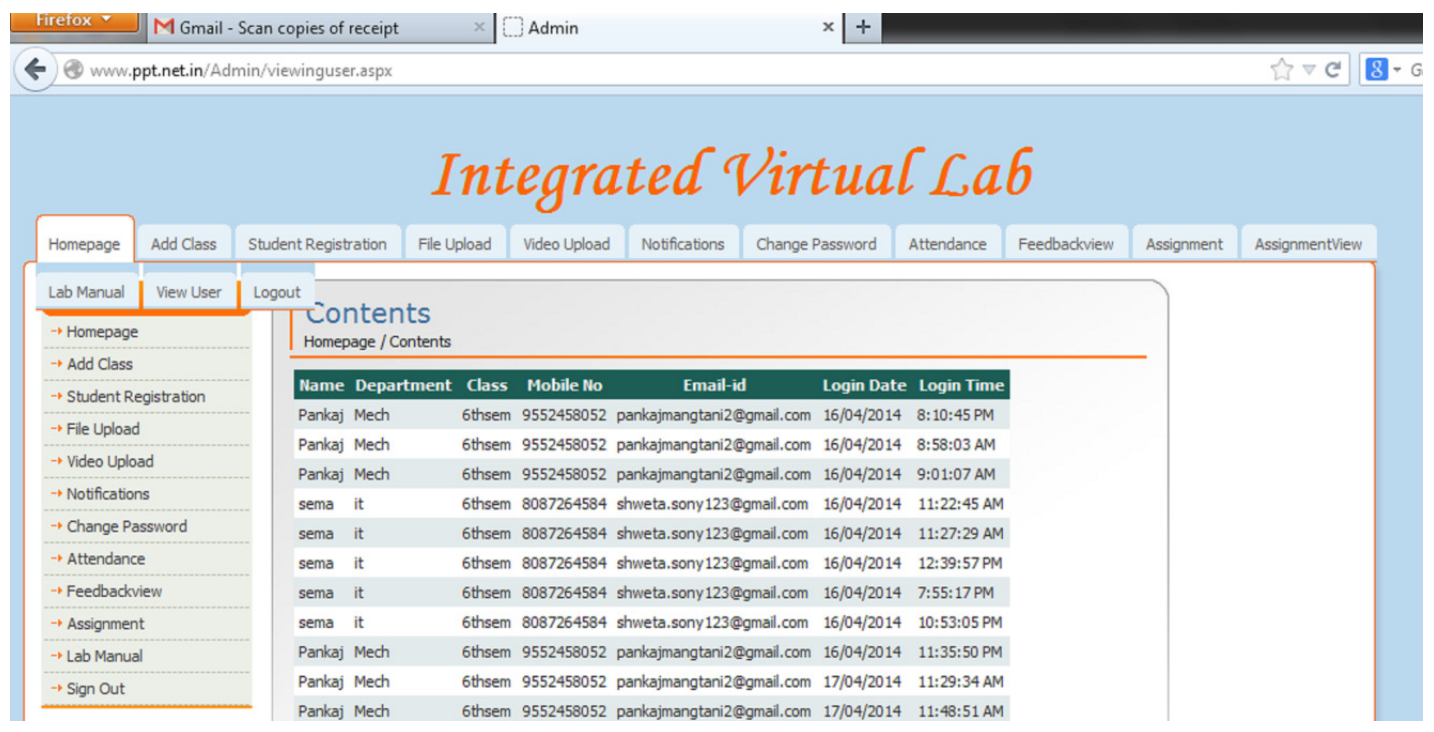

\section{User login:}

Fig 7: View user login details with date and time.

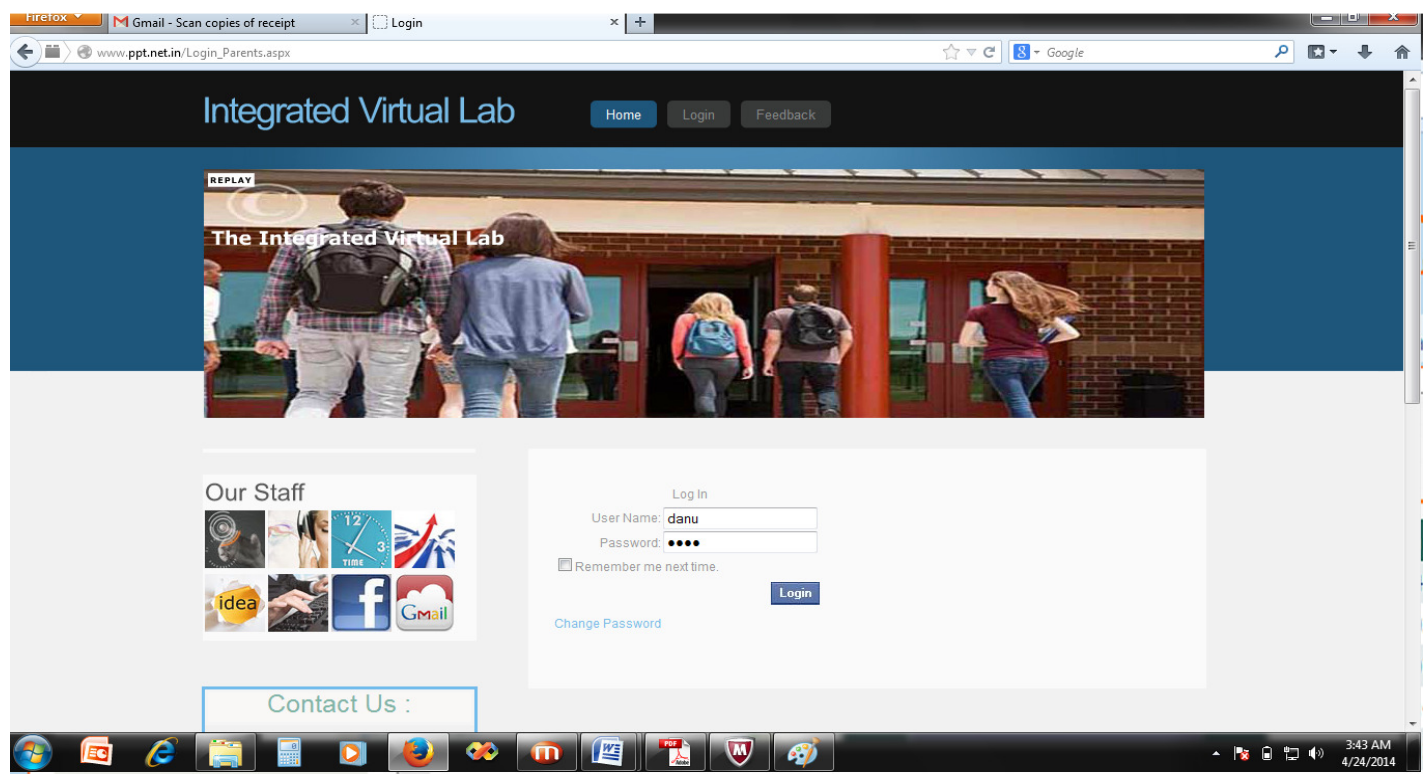

Student Menu:

Fig 8: User login with different username and password

- Admin Offline:if red symbol on user screen

- Admin Online:if green symbol on user screen 
International Journal of Network Security \& Its Applications (IJNSA), Vol.6, No.3, May 2014

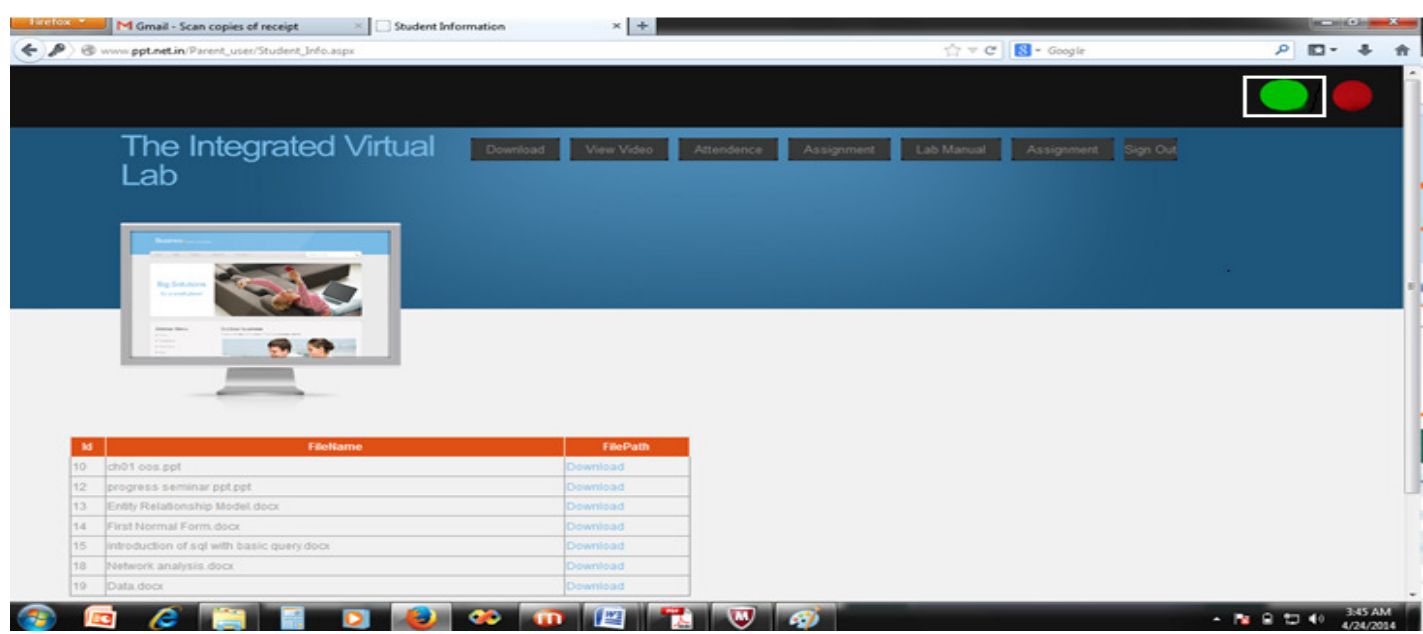

Fig 9: admin online or not shown at user side.

\section{Notice shown on user screen:}

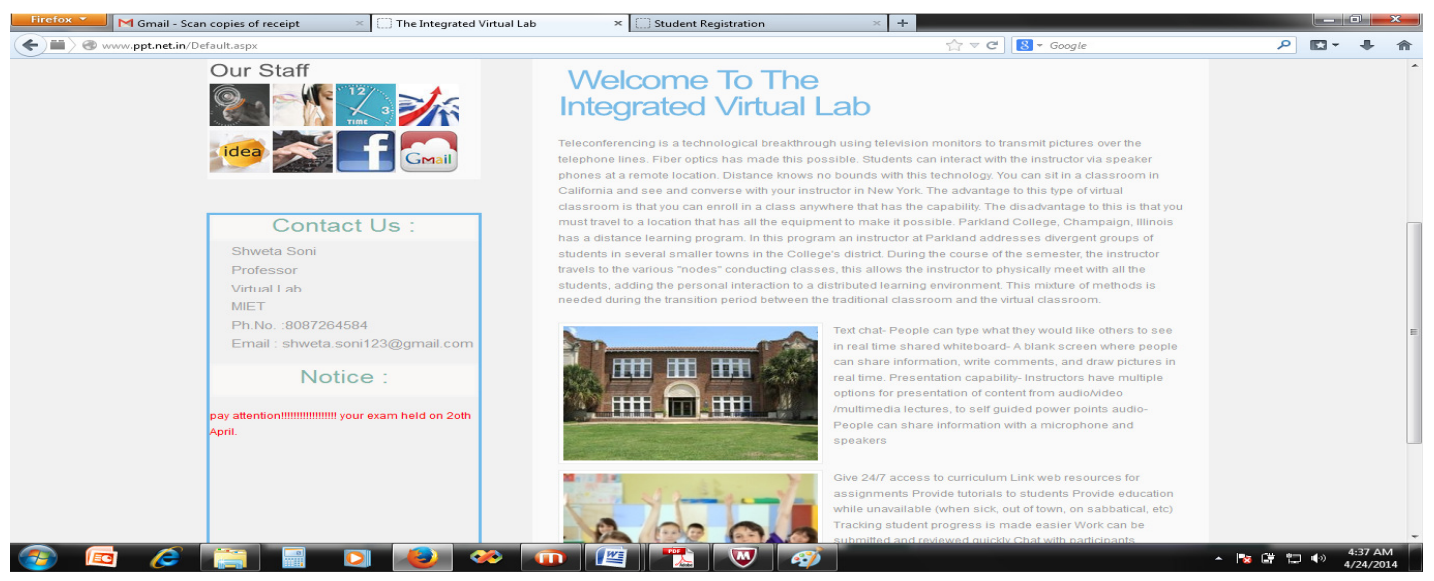

Fig 10: Notice shown on user screen

GUI's shows that how admin can login and how they have modify the database who have the authority to change the database. And then how admin can add student information to his database and add student for particular class and give their attendance also and also give their personal information to admin. And administrator can upload no of files lecture and video lecture for particular subject so that those students who cannot understand the concept in file lecture then they can download the video lecture and understand the concept of particular topic very clear by watching video more times.

\section{Advantages of proposed system}

This virtual system can be beneficial for those students who want to continue their study from elearning programmed and who cannot continue their education due to his personal reason, those who wants to continue heir education while doing job or those student who cannot attend the class due to some reason and dada is secured because user as well as admin section is protected by password so that those who are not having authority cannot not access this system. 
International Journal of Network Security \& Its Applications (IJNSA), Vol.6, No.3, May 2014

\section{Application}

This Project will be used for Our Institute.

\section{Future Scope}

To develop a system which fulfills all the Requirements of the user as per user wants? User requirements keep changing as the new technology emerges the student requirement is also changing as per technology change. Some of the future scopes that can be done to this Virtual system are.

-As the technology emerges, it is possible to upgrade the system to achieve high performance and fulfill the student requirement as the student wants.

-More modules can be added to upgrade the virtual system.

\section{Result and Analysis}

The virtual lab was used during lectures to demonstrate some of the concepts taught. They were also encouraged to download and use the virtual lab at home to complete their assignment or to study for their exams. After the course, all the students were asked to complete an anonymous questionnaire, responding to questions on a five-point scale (1-strongly disagree, 2-disagree, 3-neutral, 4-agree, 5-strongly agree). On the basis of GUI we found the result in previous paper is that the system is to be user friendly and easy to navigate with a rating ratio of 4.6/5.But in new result we found to be user friendly and easy to navigate with a rating ratio of $4.7 / 5$.so we get the system more user friendly and easy to navigate.

The results are summarized in Table I and Table II for comparative analysis. And it is also represented by individual graph and comparison graph which shows the improvement from old result to new result.

Table I

Questions and Results

\begin{tabular}{|c|c|c|c|c|c|c|}
\hline Question & 1 & 2 & 3 & 4 & 5 & AVG \\
\hline 1. Is the course challenging and interesting? & 0 & 0 & 1 & 4 & 8 & 4.5 \\
\hline $\begin{array}{l}\text { 2. Were the course's theoretical aspects clearly demonstrated by the Master Virtual } \\
\text { lab? }\end{array}$ & 0 & 0 & 1 & 10 & 2 & 4.3 \\
\hline 3. Has the Master Virtual lab enhanced your understanding of the taught subjects? & 0 & 0 & 1 & 6 & 6 & 4.4 \\
\hline $\begin{array}{l}\text { 4. Have the proposed exercise sets after each experiment assisted in discovering new } \\
\text { concepts of the subjects taught? }\end{array}$ & 0 & 1 & 4 & 3 & 5 & 3.9 \\
\hline 5.Were the Virtual lab GUI user-friendly and easy to follow? & 0 & 0 & 0 & 5 & 8 & 4.6 \\
\hline 6. Did the Virtual lab exercise increase your interest in the field of multimedia? & 0 & 0 & 1 & 7 & 5 & 4.3 \\
\hline 7. What is your overall evaluation for the course? & 0 & 0 & 1 & 7 & 6 & 4.6 \\
\hline \multicolumn{7}{|c|}{$\begin{array}{c}\text { 1-strongly disagree,2-disagree,3-neutral,4-agree,5-strongly agree } \\
\text { MARKS OUT OF } 10\end{array}$} \\
\hline
\end{tabular}


International Journal of Network Security \& Its Applications (IJNSA), Vol.6, No.3, May 2014

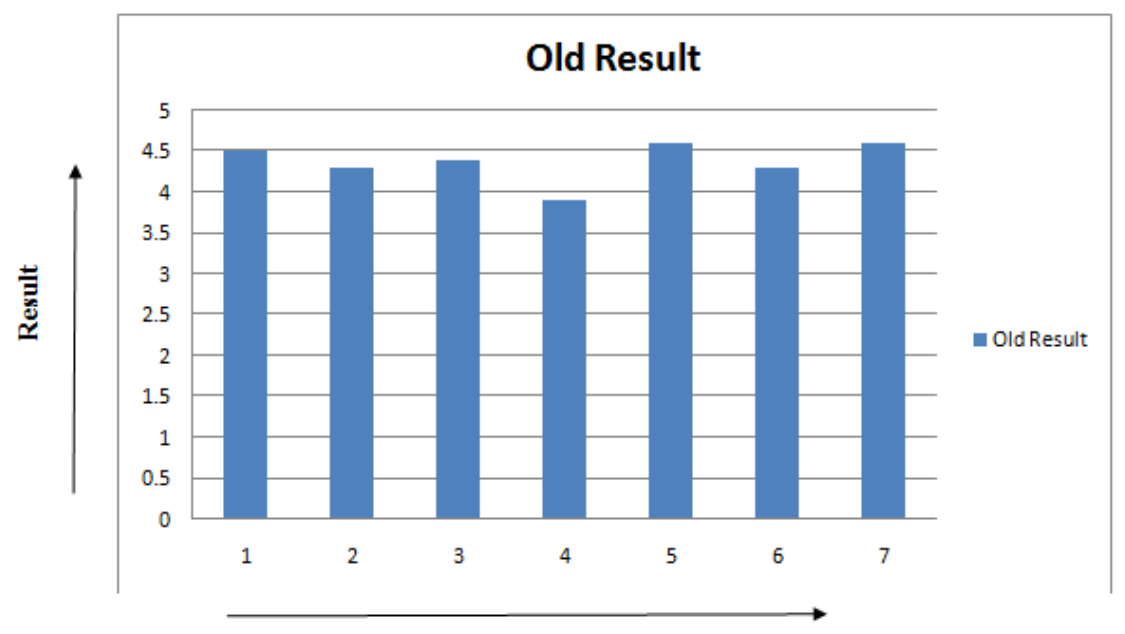

Analysis Parameter

Fig: 11. Old Result on the basis of 7 parameter (shown in table)

Table II

Questions and Results

\begin{tabular}{|l|l|l|l|l|l|l|}
\hline Question & $\mathbf{l}$ & $\mathbf{2}$ & $\mathbf{3}$ & $\mathbf{4}$ & $\mathbf{5}$ & AVG \\
\hline 1. Is the course challenging and interesting? & 0 & 0 & 1 & 5 & 8 & 4.7 \\
\hline $\begin{array}{l}\text { 2. Were the course's theoretical aspects clearly demonstrated by the Master } \\
\text { Virtual lab? }\end{array}$ & 0 & 0 & 1 & 10 & 3 & 4.6 \\
\hline $\begin{array}{l}\text { 3. Has the Master Virtual lab enhanced your understanding of the taught } \\
\text { subjects? }\end{array}$ & 0 & 0 & 1 & 6 & 6 & 4.4 \\
\hline $\begin{array}{l}\text { 4. Have the proposed exercise sets after each experiment assisted in } \\
\text { discovering new concepts of the subjects taught? }\end{array}$ & 0 & 1 & 4 & 6 & 6 & 4.2 \\
\hline $\begin{array}{l}\text { 5.Were the Virtual lab GUI user-friendly and easy to follow? } \\
\text { 6. Did the Virtual lab exercise increase your interest in the field of } \\
\text { multimedia? }\end{array}$ & 0 & 0 & 1 & 6 & 7 & 4.7 \\
\hline $\begin{array}{l}\text { 7. What is your overall evaluation for the course? } \\
\text { 1-strongly disagree,2-disagree,3-neutral,4-agree,5-strongly agree } \\
\text { MARKS OUT OF 10 }\end{array}$ & 0 & 0 & 1 & 7 & 6 & 4.7 \\
\hline
\end{tabular}


International Journal of Network Security \& Its Applications (IJNSA), Vol.6, No.3, May 2014

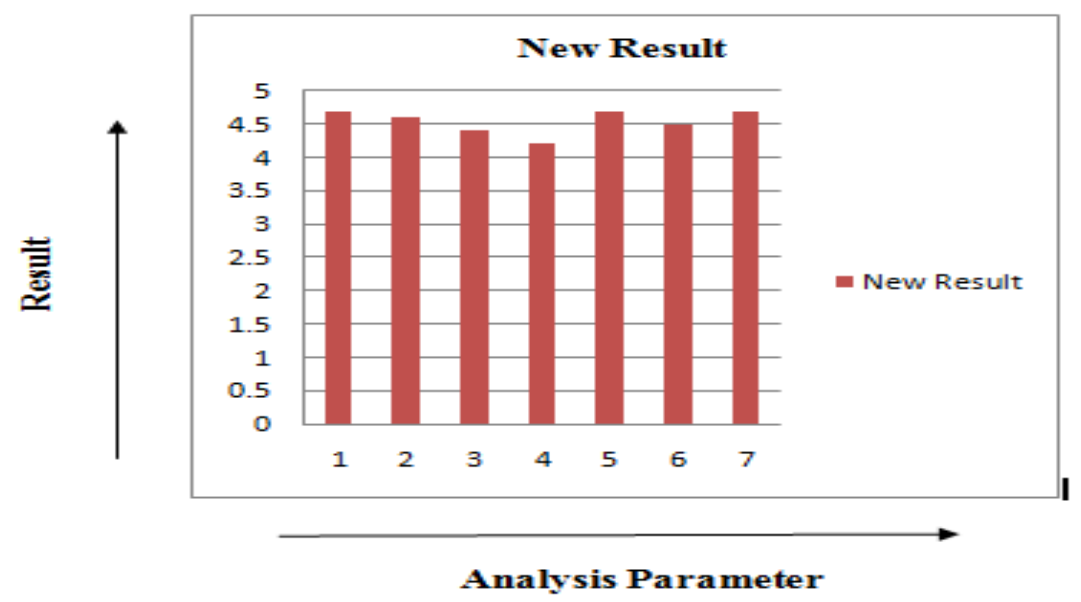

Fig: 12. New Result on the basis of 7 parameter (shown in table)

Graph shows the comparison between old result and new result on the basis of 7 parameter which is shown in the Table I and Table II respectively.

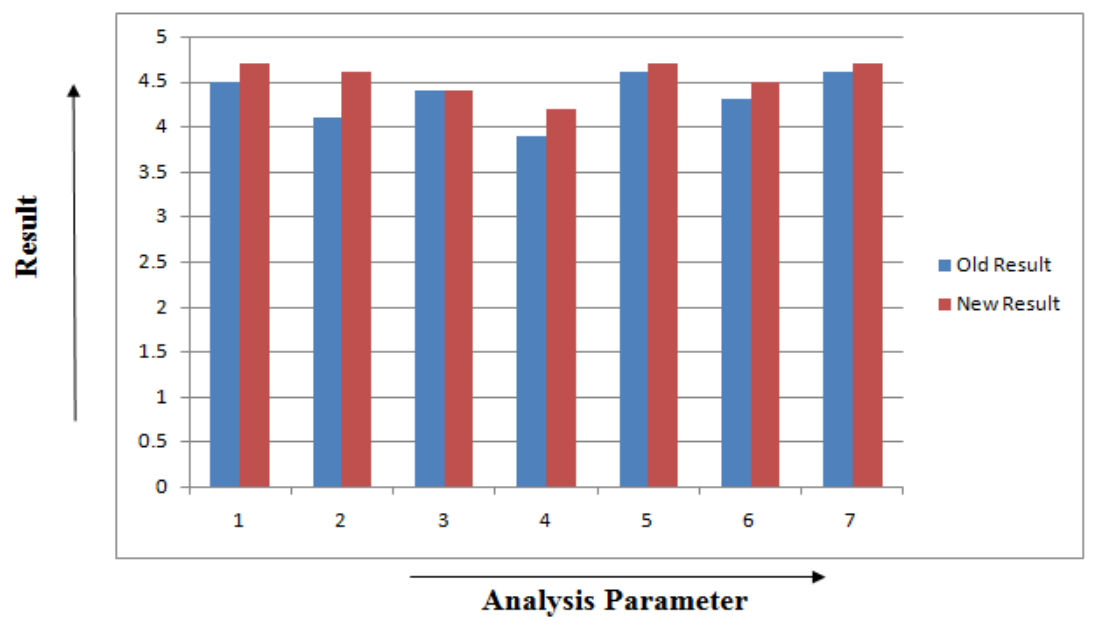

Fig: 13. Comparison between old result and new result on the basis of 7 parameter (shown in table).

\section{Conclusion}

Virtual E-Learning System has been presented an innovative idea for developing lab practices and Useful for distance learners, and providing the extra knowledge to the students. This system can be very helpful for those students who want to continue their education from e-learning programmes. Virtual e-learning system provides the basic as well as advance knowledge to the student who doesn't have any idea about the experiment or any topic this system is very useful for that type of student. If student phase the problem and not getting the concept from file study material than they have another option which is they can view the video lecture so that they can better understand the concept. And collect the notes regarding particular subject. 
International Journal of Network Security \& Its Applications (IJNSA), Vol.6, No.3, May 2014

\section{References}

[1] Rajnish Kumar, Swati Shahi "Virtual Classroom System" International Journal of Engineering Trends and Technology (IJETT) - Volume4 Issue4- April 2013

[2] Huda Mohammad Babateen" The role of Virtual Laboratories in Science Education" 20115 th International Conference on Distance Le arning and Education IPCSIT vol.12 (2011) IACSIT Press, Singapore

[3] Dimitrios S. Alexiadis ,Nikolaos Mitianoudis "MASTERS: A Virtual Lab on Multimedia Systems for Telecommunications, Medical, and Remote Sensing Applications "IEEE TRANSACTIONS ON EDUCATION, VOL. 56, NO. 2, MAY 2013.

[4] U. Rajashekar, G. C. Panayi, F. P. Baumgartner, and A. C. Bovik, "The SIVA demonstration gallery for signal, image, and video processing education,” IEEE Trans. Educ., vol. 45, no. 4, pp. 323-335, Nov. 2009.

[5] S. Shearman, S. Hong, and E. Perez, "To improve signal processing concept demonstration software, consider the interactive experience, "in Proc. 13th IEEE DSP \& 5th IEEE SPE, 2009, pp. 227-231.

[6] S. Mitra, Digital Signal Processing. New York: McGraw-Hill, 2011.

[7] J. H.McClellan, R. W. Schafer, andM. A. Yoder, "A changing role for DSP education,” IEEE Signal Process. Mag., vol. 15, no. 3, pp. 16-18,May 1998.

[8] U. Rajashekar, G. C. Panayi, F. P. Baumgartner, and A. C. Bovik, "The SIVA demonstration gallery for signal, image, and video processing education,” IEEE Trans. Educ., vol. 45, no. 4, pp. 323-335, Nov. 2002.

[9] S. Shearman, S. Hong, and E. Perez, "To improve signal processing concept demonstration software, consider the interactive experience, "in Proc. 13th IEEE DSP \& 5th IEEE SPE, 2009, pp. 227-231.

\section{Author:}

Shweta Soni Master in Technology

(Computer Science and Engineering)

G.H.Raisoni College of Engineering and Tech. for Women,

Nagpur (M.S)

Email-Id: Shwetasony1990@Gmail.Com

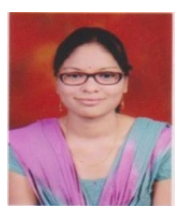

